\title{
Prevalence and Intensity of Urinary Schistosomiasis in School-age Children in Yewa North Local Government Area of Ogun State, Nigeria
}

\author{
T. O. S. Adewoga ${ }^{1^{*}}$, O. A. Akinboade ${ }^{2}$, B. O. Emikpe $^{2}$, O. Morenikeji ${ }^{3}$ \\ and A. I. Sobande ${ }^{1}$ \\ ${ }^{1}$ Department of Biology, Tai Solarin University of Education, ljebu Ode, Nigeria. \\ ${ }^{2}$ Department of Veterinary Parasitology and Pathology, University of Ibadan, Ibadan, Nigeria. \\ ${ }^{3}$ Department of Zoology, Parasitology Unit, University of Ibadan, Ibadan, Nigeria.
}

Authors' contributions

This work was carried out in collaboration between all authors. All authors read and approved the final manuscript.

Article Information

DOI: $10.9734 / A R R B / 2019 / v 31$ i330051

Editor(s):

(1) Dr. Layla Omran Elmajdoub, Department of Zoology, Faculty of Science, Misurata University, Misurata, Libya.
(2) Dr. George Perry, Dean and Professor of Biology, University of Texas at San Antonio, USA.

Reviewers:

(1) Verônica Santos Barbosa, Brasil.

(2) Prof. Mahmoud Balbaa, Alexandria University, Egypt.

(3) Dr. Dennis Makau, University of Prince Edwards Island, Canada. Complete Peer review History: http://www.sdiarticle3.com/review-history/35347

Original Research Article

Received 14 November 2017

Accepted 24 January 2018

Published 29 March 2019

\begin{abstract}
The study was carried out to determine the prevalence rate of the schistosomiasis in school-aged children of 4 selected primary schools in ljoun community of Yewa North Local Government Area in Ogun State and to evaluate the distribution of infection in terms of age and gender. A total number of 184 Urine samples were collected from the pupils and examined for the presence of over of Schistosoma haematobium, 89 of the student were positive, Yewa North local Government School 1 had the highest prevalence with $58.82 \%$, followed by Yewa North local Government School 2 with $50.0 \%$, followed by Ansarudeen Primary School with 48\%, and Yewa North local Government School 3 recorded the least with $40.0 \%$. Out of 100 sample collected for male 49 were positive with the rate of $49.0 \%$ and 84 samples collected for female 40 were positive with the rate of $47.61 \%$. The prevalence of schistosomiasis in relation to age groups. Age group $10-12$ years recorded the highest prevalence with $54.21 \%$ followed by age $7-9$ with $52.38 \%$, followed by age $13-15$ with
\end{abstract}


$37.73 \%$ and age group $16-18$ years had the lowest rate (33.33\%). From the stated hypothesis, It can be affirmed that there is a significant difference between age and gender of the children in relation to schistosomiasis. There is a need for health education in the rural areas, designed to discourage the pupil's contact with surface water sources and provision of portable water supply.

Keywords: Prevalence and intensity; ljoun; schistosoma; gender; age.

\section{INTRODUCTION}

Schistosomiasis is a chronic water-borne parasitic disease caused by blood flukes (trematode worms) of the genus Schistosoma. It is also called Bilharziasis [named after a German Pathologist, Theodore Bilharzia who first identified the parasite in Egypt in 1851 [1]. The disease is second to malaria as a health problem in Africa. Over 243 million people in 78 countries and territories in the world are affected by the disease, occurring mostly in the tropical and subtropical areas, especially in poor communities without access to safe drinking water and adequate sanitation. It is estimated that at least $90 \%$ of those requiring treatment for Schistosomiasis live in Africa [2] Schistosomiasis occurs in most parts of the tropics and subtropics, affecting some 200 million persons and is most prevalent in sub-Saharan Africa. It was also observed by Alam and Okwori, 2012 that highly disease-endemic areas, prevalence rates can exceed $50 \%$ among the local population and high rates have been reported among expatriates living in such areas and even among short-term travelers to these areas. The distribution of the diseases is focal and often restricted to areas with peculiar ecology which favors its transmission.

In Nigeria, about five species (SPP) of the genus Schistosoma are pathogenic to man. These species (SPP) include Schistosoma heamatobium, Schistosoma mansoni, Schistosoma japanicum, Schistosoma intercalatum and Schistosoma Mekong. In Africa, S.haematobium is known to be transmitted by the planorbid snail Bulinus species, including $B$. globosus, B. Africanus, $B$. nasutus and $B$. truncatus. Also, B. forskalii and B.senegalensis have been incriminated as intermediate host of S. haematobium.

Water contact activities and traditional agricultural practices are reported as factors responsible for the distribution of the disease and its snail vectors World Health Organization [2] estimated that worldwide 180 million people live in endemic areas and 90 million are infected with the parasites, most of these live in sub-Saharan Africa. Roughly 70 million people suffer from hydronephrosis (an accumulation of urine in the kidney due to obstruction of ureter). It is also estimated that 150,000 people die each year from resultant renal failure and an unknown significant number of bladder and other genital urinary cancers [2].

The economic effects and health implications of schistosomiasis are extensive. Higher disease rates occur in children [3] with infection frequently found in those less than 14 years in many risk areas [4]. In many places, there is a higher incidence of infection in young boys and girls, this is as result of increase and frequent contact with water bodies compared to other population groups in a culture where girls and women typically fetch water for household use and young boys often play in stagnant or moving water. Conversely, some other parts where men primarily fetch water, engage in fishing and irrigation activities do have higher rates of schistosomiasis, these differential rates of transmission depend on cultural practices. Recent studies revealed the disease to be endemic among individuals in our rural areas in most states. It is a rural disease but can also be found in the urban area due to rural-urban migration. The disease is the most prevalent of the water-borne parasitic diseases and one of the greatest risks to health in rural areas of developing countries. Human becomes infected by the penetration of the larval stage, cercaria, through the unbroken skin. Schistosomiasis in Africa is a very serious public health problem and it is endemic in Nigeria.

Schistosomiasis is one of the major public health problems facing developing countries, with school-age children at greatest risk [5]. This study aimed at assessing the prevalence and intensity of the infection in some 


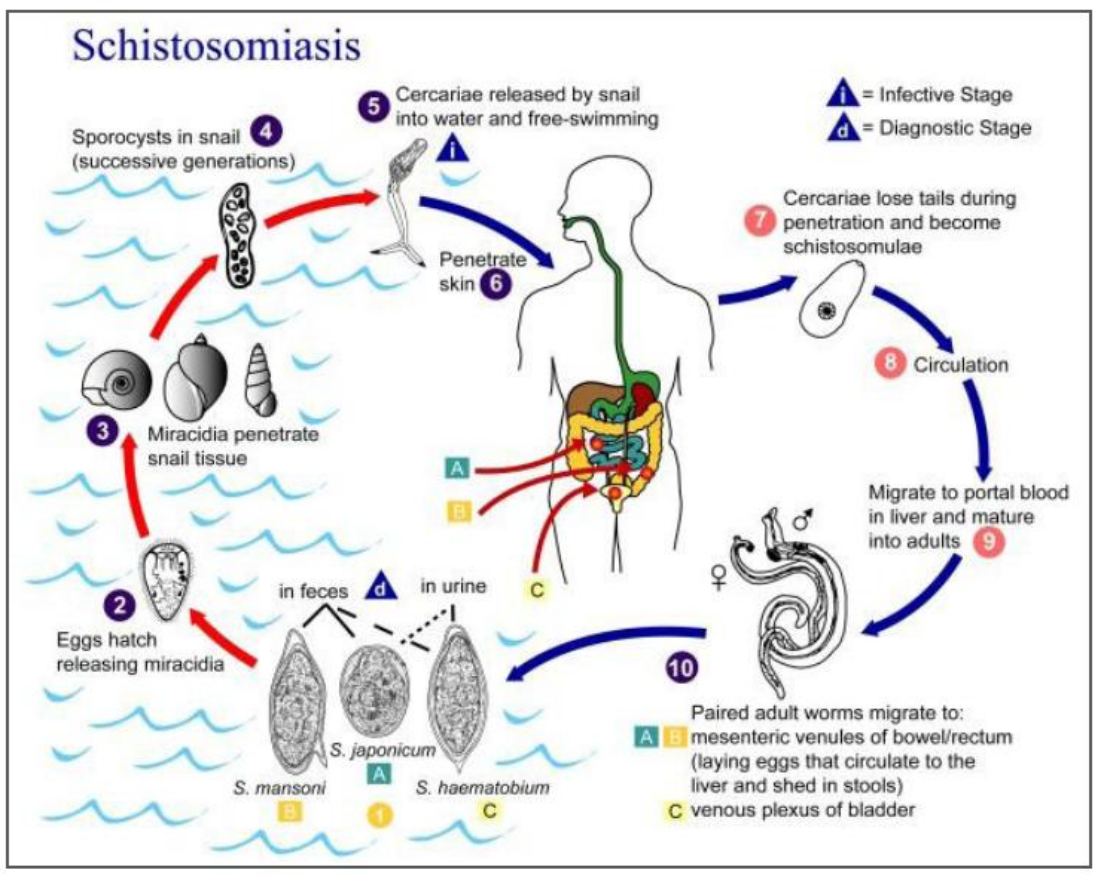

Fig. 1. The Schistosomiasis life cycle Source: WHO, 2006

selected schools since school children are one of the major risk groups for the transmission of the infection.

\subsection{The Objectives of the Study}

- To determine the prevalence and intensity rate of the infection in school-aged children of 4 selected primary schools in Yewa North Local Government Area in Ogun State.

- To evaluate the distribution of infection in terms of age and gender.

\subsection{Significance of the Study}

$\checkmark$ The significance of the study is to provide data that will contribute to a more multipronged approach to health service provision, prevention, and control of schistosomiasis.

$\checkmark$ The findings of this study will significantly contribute to improving the health of learners in Yewa North Local Government in ljoun.

\subsection{Hypothesis}

$\checkmark \mathbf{H}_{0}$ : There is no significant difference between age and gender of the children in relation to schistosomiasis. $\checkmark \quad H_{1}$ : There is a significant difference between age and gender of the children in relation to schistosomiasis.

\subsection{Brief Description of the Study Area}

The study was carried but in public primary schools of Yewa North Local Government in ljoun Community in Ogun State South western Nigeria. It is a community under Ayetoro town (Lat.70, 13' N, and Long. 30 02' E) the Headquarters of Yewa North Local Government Areas in Ogun state. The community share boundary between Republic of Benin and Nigeria. It has an estimated population of 300,000 according to 2006 population census. The study area has one public primary school and one primary health center, the people predominant occupation are farming, fishing and trading. Their sources of water are rivers, streams, and ponds.

\section{MATERIALS AND METHODS}

MATERIALS-Base on the practical approaches of this study, the materials used are; Test tube, Centrifuge, Urine sample, Cotton wool, MC Slides, Cover slip, Microscope, Gloves, Collecting bottles. 


\subsection{Methods}

a) Macroscopic examination -All urine samples were macroscopically examined for their appearance

b) Microscopic examination - The urine were screened for the presence of eggs using wet preparation method and concentration technique [6]

c) Urine microscopy - The procedures for the urine examination are as follows:

1. The urine specimens were thoroughly agitated, $10 \mathrm{ml}$ of each sample taken, centrifuge at 3,5000rpm for 5minutes;

2. The supernatant was discarded and the whole sediment was transferred to a clean slide and covered with cover glass;

3. The entire sediment was examined under the microscope using $\times 10$ objective lens with the condenser iris closed sufficiently to give good contrast;

4. The results were analyzed as egg/10ml urine according to age and sex of pupil;

5. The results were interpreted according to Cheesbrough [7], any urine sample containing more than 50 eggs in $10 \mathrm{ml}$ of urine indicates a heavy infection of Schistosoma haematobium.

\subsection{Statistical Analysis}

Frequency distribution tables, percentage prevalence of urinary schistosomiasis infections were estimated using standard formulae. Chi- square test was used to compare the differences in prevalence of infection between age and gender of the children using SPSS version 20

\section{RESULTS AND DISCUSSION}

\subsection{Test of Hypothesis}

\subsubsection{Hypothesis}

$\mathbf{H}_{0}$ : There is no significant difference between age and gender of the children in relation to schistosomiasis.

$\mathbf{H}_{1}$ : There is a significant difference between age and gender of the children in relation to schistosomiasis.

The critical value from Chi-Square Table at 0.05level of significance

$$
\begin{aligned}
d f= & (r-1)(c-1) \\
& (8-1)(4-1) \\
& (7)(3) \\
& 21
\end{aligned}
$$

21 under $.05=32.67$

\subsection{Decision Rule}

$$
\begin{aligned}
& \text { If } X^{2} C>X^{2} T-\text { reject } H_{0} \\
& \text { If } X^{2} C<X^{2} T-\text { accept } H_{1}
\end{aligned}
$$

Since $X^{2} C(405.346)>X^{2} C \quad(32.67), H_{0}$ will be rejected while $H_{1}$ will be accepted.

Table1. Prevalence of Urinary Schistosomiasis base on school, gender, and age

\begin{tabular}{llll}
\hline Items & Number examined & Number positive & Prevalence\% \\
\hline 1. Name of school & & & \\
\hline - Yewa North Local Government School 1 & 50 & 25 & 50 \\
- Yewa North Local Government School 2 & 50 & 20 & 40 \\
- Yewa North Local Government School 3 & 34 & 20 & 58.82 \\
- Ansarudeen Primary School & 50 & 24 & 48 \\
\hline Total & 184 & 89 & 48.36 \\
\hline 2. Gender & & & \\
\hline - Male & 100 & 49 & 49 \\
- Female & 84 & 40 & 47.61 \\
\hline Total & 184 & 89 & 48.36 \\
\hline 3. Age & & & \\
\hline - 7-9 & 42 & 22 & 52.38 \\
- 10-12 & 83 & 45 & 54.21 \\
- 13-15 & 53 & 20 & 37.73 \\
- 16-18 & 6 & 2 & 33.33 \\
\hline Total & 184 & 89 & 48.36 \\
\hline
\end{tabular}


Table 2. Intensity of urinary schistosomiasis

\begin{tabular}{lll}
\hline Name of school & Egg Count & Intensity \\
\hline Yewa North Local Government School 1 & 98 & Heavy \\
Yewa North Local Government School 2 & 180 & Severe \\
Yewa North Local Government School 3 & 99 & heavy \\
Ansarudeen Primary School 4 & 234 & severe \\
\hline
\end{tabular}

Table 3. Age * gender cross tabulation

\begin{tabular}{llllll}
\hline & $\begin{array}{l}\text { Male } \\
\text { positive }\end{array}$ & $\begin{array}{l}\text { Male } \\
\text { negative }\end{array}$ & \multicolumn{2}{c}{ Gender } & Total \\
& 22 & 0 & 0 & 0 & \\
\hline Age 7-9 yrs Positive & 20 & 0 & 0 & 0 & 22 \\
$7-9$ yrs Negative & 7 & 38 & 0 & 0 & 20 \\
10-12 yrs Positive & 0 & 13 & 25 & 0 & 45 \\
$10-12$ yrs negative & 0 & 0 & 15 & 5 & 20 \\
$13-15$ yrs positive & 0 & 0 & 0 & 33 & 33 \\
$13-15$ yrs negative & 0 & 0 & 0 & 2 & 2 \\
$16-18$ yrs Positive & 0 & 0 & 0 & 4 & 4 \\
16-18 yrs Negative & 0 & 51 & 40 & 44 & 184 \\
\hline Total & 49 & & & & \\
\hline
\end{tabular}

Table 4. Chi-square tests

\begin{tabular}{|c|c|c|c|}
\hline & Value & Df & $\begin{array}{l}\text { Asymp. Sig. } \\
\text { (2-sided) }\end{array}$ \\
\hline Pearson Chi-Square & $405.346^{a}$ & 21 & .000 \\
\hline Likelihood Ratio & 398.315 & 21 & .000 \\
\hline $\begin{array}{l}\text { Linear-by-Linear } \\
\text { Association }\end{array}$ & 160.037 & 1 & .000 \\
\hline $\mathrm{N}$ of Valid Cases & 184 & & \\
\hline
\end{tabular}

\subsection{Discussion}

Out of 184 urine samples collected 89 were positive while 95 were negative in the study area as shown in Table 1. The prevalence of schistosomiasis in relation to schools. Yewa North local Government School 1 had the highest prevalence with $58.82 \%$, followed by Yewa North local Government School 2 with $50.0 \%$, followed by Ansarudeen Primary School 4 with $48 \%$, and Yewa North local Government School 3 recorded the least with $40.0 \%$. The prevalence of schistosomiasis according to the gender of the students in the four schools. out of 100 sample collected for male 49 were positive with the rate of $49.0 \%$ and 84 samples collected for female 40 were positive with the rate of $47.61 \%$. The prevalence of schistosomiasis in relation to age groups. The result indicates that there is an increase in prevalence with an increase in age. Age group10 -12 years recorded the highest prevalence with $54.21 \%$ followed by age $7-9$ with $52.38 \%$, followed by age $13-15$ with 37.73 and age group $16-18$ years had the lowest rate $(33.33 \%)$. From the stated hypothesis above, with, It can be affirmed that there is significant difference between age and gender of the children in relation to schistosomiasis.

\section{CONCLUSION}

Schistosomiasis is still endemic in some part of Nigeria especially in Yewa North local government, join as a case study. The only source of water in this study area is a river. The control of schistosomiasis requires an integrated process. However, chemotherapy with Praziquantel is the mainstay for the control of the disease in the short-term. Poverty on the part of infected subjects, lack of deployment of political and financial resources by disease-endemic countries is the major factors limiting the control of the disease. The current global economic recession has contributed in reducing financial resources available for the control of the infectious diseases.

\section{RECOMMENDATION}

The following recommendations are suggested for the control of schistosomiasis;

- The government should create an awareness program for this disease and delivery of Praziquante (PZQ) should be integrated into the programme.

- The government should make pipe borne water available for the area that the 
disease is endemic to reduce the chances of coming in contact with cercariaeinfested water bodies.

\section{ETHICAL APPROVAL}

As per international standard or university standard written ethical approval has been collected and preserved by the author(s).

\section{COMPETING INTERESTS}

Authors have declared that no competing interests exist.

\section{REFERENCES}

1. WHO. Schistosomiasis and soiltransmitted helminth infections. Geneva, World Health; 2001.

2. WHO. Artemether protects against schistosome infection. Publication. 2003; 62:1-2.
3. Gryseels B, Polman K, Clerinx, et al. Human schistosomiasis. Lancet. 2006; 368:110618

Available:http://www.ngex.com/nigeria/plac es/states/yobe.htm

[Accessed on $20^{\text {th }}$ December, 2011]

4. WHO. Schistosomiasis. Fact Sheet No 115. Geneva; 2007.

Available:http://www.who.int/entity/mediac entre/factsheets/fs115/en

[Accessed 23 ${ }^{\text {rd }}$ December, 2011]

5. Uneke CJ, Oyibo PG, Ugwuoru CD, Nwanokwai AP, lloegbunam RO. Urinary schistosomiasis among school age children in Ebonyi State, Nigeria. The Internet Journal of Laboratory Medicine. 2007;2(1).

6. Monica CD. District laboratory in tropical countries part 1. Cambridge University Press UK. 2004;56-57.

7. Cheesebrough M. District laboratory practice in tropical countries $2^{\text {nd }}$ Edition. 2005;106-108.

(c) 2019 Adewoga et al.; This is an Open Access article distributed under the terms of the Creative Commons Attribution License (http://creativecommons.org/licenses/by/4.0), which permits unrestricted use, distribution, and reproduction in any medium, provided the original work is properly cited.

The peer review history for this paper can be accessed here: http://www.sdiarticle3.com/review-history/35347 